\title{
Drug resistance mechanisms of cancer stem-like cells and their therapeutic potential as drug targets
}

\author{
Takahiko Murayama, Noriko Gotoh \\ Division of Cancer Cell Biology, Cancer Research Institute, Kanazawa University, Kanazawa 920-1192, Japan.
}

Correspondence to: Prof. Noriko Gotoh, Division of Cancer Cell Biology, Cancer Research Institute, Kanazawa University, Kakuma-machi, Kanazawa 920-1192, Japan. E-mail: ngotoh@staff.kanazawa-u.ac.jp

How to cite this article: Murayama T, Gotoh N. Drug resistance mechanisms of cancer stem-like cells and their therapeutic potential as drug targets. Cancer Drug Resistance 2019;2:457-70. http://dx.doi.org/10.20517/cdr.2019.36

Received: 2 May 2019 First Decision: 28 May 2019 Revised: 19 Jun 2019 Accepted: 28 Jun 2019 Published: 19 Sep 2019

Science Editor: Miroslav Blumenberg Copy Editor: Cai-Hong Wang Production Editor: Jing Yu

\begin{abstract}
Despite of recent advances in cancer research and development of new anti-cancer drugs, tumor patients' prognoses have not yet been improved well enough. Treatment failure of tumors is highly attributed to the drug resistance of a small population of cancer cell known as cancer stem-like cells (CSCs). CSCs also have the self-renewal activity and differentiation potency, conferring strong tumorigenicity on them. Therefore, development of CSC targeting therapy is urgently needed in order to overcome possible recurrence and metastasis by them after therapy. CSCs show some characteristic features that are not observed in other differentiated cancer cells, which give them higher resistance against conventional chemotherapy or radiotherapy. Targeting such specific features could be useful for CSC eradication. This review will summarize the recent advances in the study of CSC characteristics along with the promising therapeutic strategies targeting them.
\end{abstract}

Keywords: Cancer stem-like cell, drug resistance, epithelial-to-mesenchymal transition, hypoxia, quiescence

\section{INTRODUCTION}

Tumors are composed of highly heterogeneous populations, in which the existence of tumor initiating cells or cancer stem-like cells (CSCs) has been suggested. CSCs are thought to possess high tumorigenic potential because they show the normal tissue stem-like properties including the self-renewing activity and the potency to generate differentiated cell populations ${ }^{[1]}$. Multiple studies have also shown that the CSC population is highly resistant to conventional chemotherapeutic agents and radioactive therapies due to

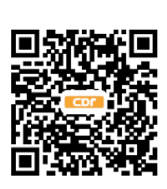




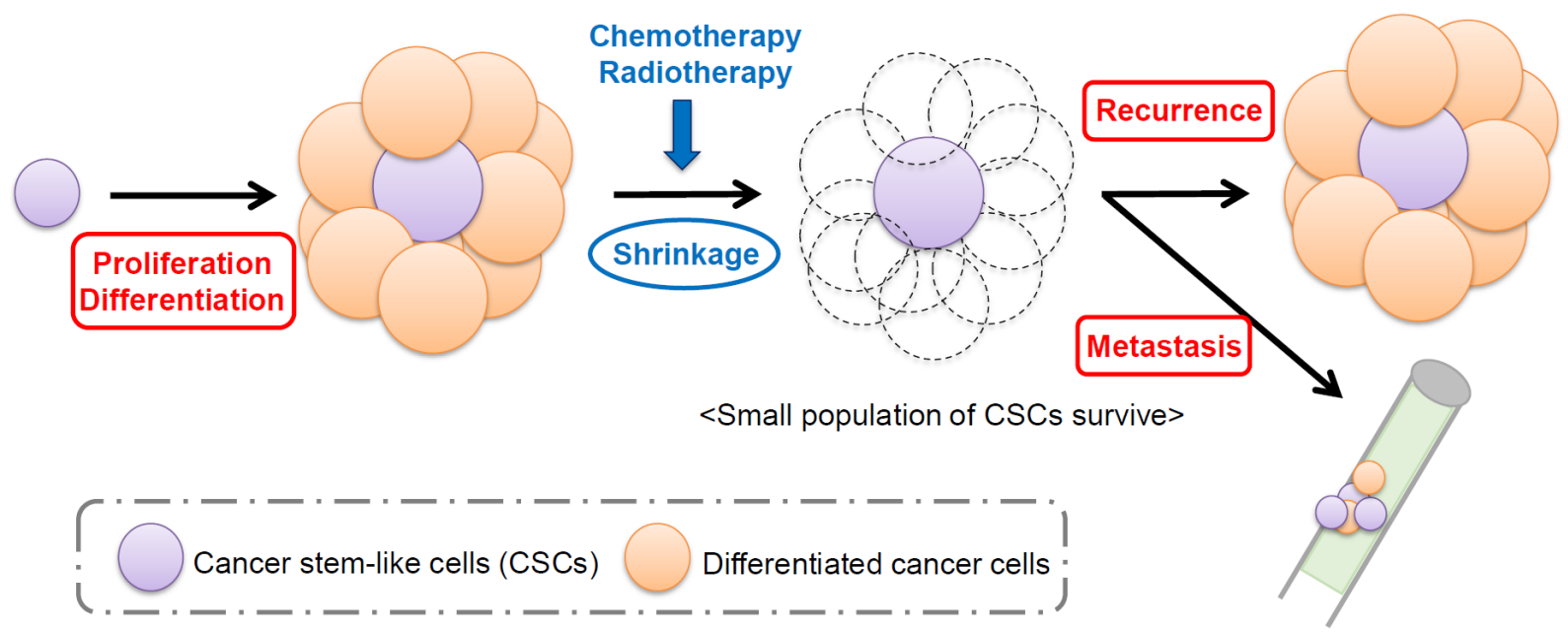

Figure 1. Schematic model of CSC-derived recurrence and metastasis. CSCs are thought to possess high tumorigenic potential because they have the self-renewing activity and the potency to generate differentiated cell populations. CSCs also survive after treatment with chemotherapy or radiotherapy, which leads to recurrence and metastasis, two major causes of poor patient prognosis. CSCs: cancer stem-like cells

many kinds of properties specific to them ${ }^{[2-4]}$. Therefore, it is very likely that CSCs survive after treatment with conventional therapy regimens, and recurrences and metastasis, which are the major cause of poor patient prognosis, are driven by those cells, even if the number of survived cancer cells reached to an undetectable level [Figure 1].

In order to overcome the therapy resistance of CSCs, deep understanding on their biologic features is indispensable. Identification of CSC surface markers and development of functional assays including sphere forming assay, in vivo limiting dilution assay and aldefluor assay, have helped researchers to shed light on CSC features ${ }^{[5,6]}$, although there are still much to be elucidated.

In this article, we review current knowledge on the mechanisms by which CSCs show higher therapy resistance and introduce some therapeutic strategies targeting the features of CSCs.

\section{REPRESENTATIVE PROPERTIES OF CSCS}

The existence of CSCs were first indicated in 1994 by Lapidot et al. ${ }^{[7]}$. They separated patient-derived acute myeloid leukemia (AML) cells based on the expression of $\mathrm{CD} 34$ and $\mathrm{CD} 38$, which are the important markers for detection of immature cells in normal bone marrow. When transplanted into severe combined immuno-deficient mice, $\mathrm{CD} 34^{+} \mathrm{CD} 38^{-}$subpopulation formed tumors much more efficiently than $\mathrm{CD} 34^{+} \mathrm{CD} 38^{+}$or $\mathrm{CD} 34^{-}$subpopulations. Furthermore, tumors formed by $\mathrm{CD} 34^{+} \mathrm{CD} 38^{-}$subpopulation precisely replicated many aspects of human AML. These results suggested that AML stem cells are included in $\mathrm{CD}_{34} 4^{+} \mathrm{CD} 38^{-}$fraction. Then, in 1997, the concept of CSCs was firmly established by focusing the similarity with normal stem cells by Bonnet et al.$^{[8]}$. After a decade, existence of CSCs started to be confirmed also in solid tumors including, but not limited to, breast cancer $^{[9]}$, glioblastoma ${ }^{[10]}$, prostate cancer $^{[11]}$, colorectal cancer ${ }^{[12-14]}$ and lung cancer ${ }^{[15]}$.

Although prospective markers to identify CSCs differ among tumor types, CSCs in many kinds of tumors share some important features; higher tumorigenic potential, potency to generate highly heterogeneous population of cancer cells, capacity of serial tumor propagation and higher drug resistance ${ }^{[16-19]}$. Selfrenewing ability and multi differentiation potency are special features of normal tissue stem cells. Therefore, some researchers think that CSCs arise when tumorigenic mutations accumulate in normal 
stem cells. However, others think that CSCs are produced by differentiated cancer cells which undergo dedifferentiation into stem-like state, because data suggesting that cancer cells have plasticity are also accumulating $^{[20]}$. Hence, the origin of CSCs still remains to be elucidated.

In CSCs of many types of tumors, stemness related signaling pathways including Wnt, Hedgehog and Notch are often activated ${ }^{[21]}$. Wnt signaling has been reported to be involved in the embryogenesis and organ development by regulating self-renewal and differentiation of normal stem cells ${ }^{[22]}$. When Wnt binds to frizzled receptor, it downregulates the function of AXIN/glycogen synthase kinase-3 (GSK-3)/ adenomatous polyposis coli (APC) complex, leading to stabilization of $\beta$-catenin. $\beta$-catenin binds to TERT promoter region and directly enhance TERT expression, leading to maintain long telomeres, which is one of the major hallmarks of CSCs ${ }^{[23]}$.

Hedgehog signaling is also important for the embryogenesis and the repair of normal tissues ${ }^{[24]}$. When Hedgehog ligands including Sonic Hedgehog, Indian Hedgehog or Desert Hedgehog, bind to the Smoothened receptors, GLI transcription factor is activated by the receptor. The activated GLI localizes into nucleus and induce expression of genes involved in cell survival and proliferation ${ }^{[25]}$. Activation of Hedgehog signaling could be the cause of epithelial-to-mesenchymal transition (EMT), a representative characteristic of $\operatorname{CSCs}^{[26,27]}$.

Notch signaling is an evolutionarily highly conserved signaling mechanism, which is critical for cell proliferation, differentiation, organ development and homeostasis ${ }^{[28]}$. Unlike Wnt or Hedgehog signaling, Notch signaling occurs through cell-cell communication. When a transmembrane ligand on one cell binds to a transmembrane receptor on a neighboring cell, the receptor is cleaved and interact with nuclear factors to regulate gene expression. In mammals, there are four types of receptors, Notches 1-4, and five types of ligands, delta-like ligand 1 (DLL1), DLL3, DLL4, Jagged-1 and Jagged- $2^{[29]}$. Although dependency on each type of ligand and receptor is varied among different tumor types, activation of Notch signaling has been interrelated with cancer stemness ${ }^{[30-33]}$. Therefore, Notch signaling inhibitors have been developed ${ }^{[34-36]}$, and the efficacy of combinational therapy with conventional anti-cancer drugs is investigated.

\section{THERAPY RESISTANCE OF CSCS}

Drug resistance of cancer cells is the main reason of poor prognosis of tumor patients. If cancer cells can survive after therapy, they give rise to relapse and metastasis, which are the almost all the causes of cancer related death ${ }^{[37]}$.

As identifying CSCs correctly is still difficult, the relationship between CSCs and drug resistance is not completely clear. However, accumulating evidences have suggested that CSCs possess multi-drug resistance and contribute to incomplete therapeutic responses of tumors. One example indicating CSCs contribution to drug resistance is that when tumors were treated with conventional anti-cancer drugs such as cisplatin, small number of cancer cells survived and the proportion of cells showing the CSC properties significantly increased ${ }^{[38,39]}$. Another example is that patient prognosis is much worse when cancer cells in tumor strongly express CSC markers like CD133 ${ }^{[40-44]}$. Furthermore, CSCs isolated from clinical breast tumor samples were reported to show strong resistance to various chemotherapeutic drugs ${ }^{[42]}$.

Higher resistance of CSCs is observed not only for chemotherapy but also for radiotherapy. Bao et al. . $^{[3]}$ reported that once patients were irradiated in therapeutic regimen, survived glioblastoma cells became more resistant to irradiation, suggesting that CSCs were not eradicated and started to self-renew after therapy. Very recently, Carruthers et al. ${ }^{[45]}$ shed light on how glioblastoma CSCs possess higher resistance to radiotherapy. They found that DNA damage response is constitutively activated in CSCs, because of higher 


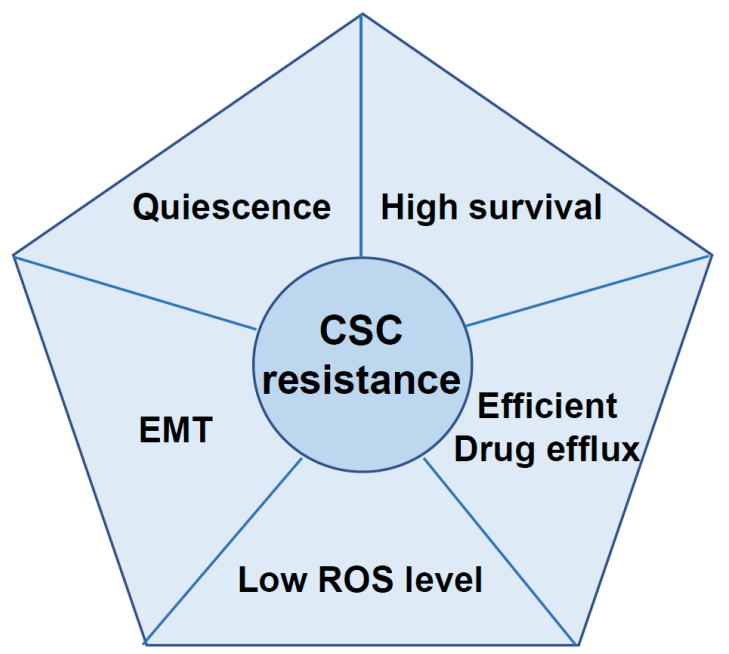

Figure 2. Characteristic of CSCs contributing to higher drug resistance. Higher therapeutic resistance of CSCs is maintained by many features including quiescence, epithelial-to-mesenchymal transition, low ROS level, efficient drug efflux ability and upregulated survival signaling. CSCs: cancer stem-like cells

level of replicative stress generated in those cells. Also, based on the findings, they indicated that inhibition of DNA damage checkpoint pathway would be the promising strategy to target CSCs. Not limited to enhanced DNA damage response, CSCs have many different mechanisms to exhibit their higher therapy resistance as described below [Figure 2].

\section{MECHANISMS OF CSCs' THERAPY RESISTANCE AND THEIR POTENTIAL AS THERAPEUTIC TARGETS}

Some features of CSCs have been linked to the higher drug resistance of the cells. Most of the features are shared with normal tissue stem cells, but some are limited to CSCs. In order to develop efficient and nonharmful therapeutic strategies, we have to identify and target therapy resistant mechanisms that are highly specific to CSCs.

\section{Quiescence}

CSCs are thought to be in a dormant state (or referred to as Go phase) especially after tumors are formed. Therefore, it is difficult to eliminate them with conventional anti-cancer drugs or radioactive rays which target actively proliferating cells ${ }^{[46]}$. Quiescent cells also have long time to repair DNA damage induced by chemotherapeutic drugs or radioactive rays. In fact, a variety of studies have shown that CSCs are highly resistant to DNA damages due to its ability to repair them ${ }^{[1,47]}$. In addition to time for repair, CSCs show enhanced DNA repair activity, which also contribute to its higher resistance ${ }^{[45]}$.

To overcome therapy resistance derived from quiescence of CSCs, researchers are trying to develop strategies to wake them up ${ }^{[48]}$. Takeishi et al. ${ }^{[49]}$ made it clear by using a mouse model that genetic ablation of F-box protein Fbxw7 made leukemia CSCs enter the cell cycle. Therefore, combinational therapy of Fbxw7 depletion and anti-cancer drug imatinib attenuated leukemia development not only during treatment but also after discontinuation of medication. This result strongly suggests that CSCs can be eliminated if they are not in a dormant state. In addition, Prost et al ${ }^{[50]}$ reported that agonists of peroxisome proliferatoractivated receptor- $\gamma$ also inhibits leukemia CSCs to stay in a non-proliferating state by decreasing expressions of hypoxia-inducible factors $2 \alpha\left(\mathrm{HIF}_{2} \alpha\right)$ and CITED26, which are key modulators of the quiescence and stemness. Their results also show that waking up strategy is really promising to eradicate CSC pool. 


\section{Epithelial-to-mesenchymal transition}

EMT and its counterpart, mesenchymal-to epithelial transition are the essential processes of embryonic morphogenesis ${ }^{[51]}$. Not limited to normal tissue stem cells, EMT is also important features of CSCs. Actually, when EMT programme was induced in human mammary epithelial cells, the cells obtained the ability to form mammary tumors in mice ${ }^{[52]}$. They also showed that cells that undergone EMT acquired a $\mathrm{CD} 44^{\text {high/ }} \mathrm{CD} 24^{\text {low }}$ expression pattern, formed mammospheres and made soft agar colonies efficiently. As these features are often linked to breast CSCs, the EMT programme may contribute to maintain the CSC features. In addition, loss of epithelial features has been strongly linked to the ability of metastasis and patient poor prognosis ${ }^{[53,54]}$.

Cells which undergo EMT programme sometimes get into a dormant state, which is one mechanism in which EMT contributes to obtaining therapy resistance. However, this resistance can be attributed to various mechanisms. Farmer et al.$^{[55]}$ reported that upregulation of stroma cell-related gene sets, which can be induced by EMT, correlated with higher drug resistance of breast cancer. Based on the findings, they suggested anti-stromal agents may offer chances to overcome drug resistance. Other research groups are now focusing on the way to inhibit EMT. EMT can be prevented by interrupting the signaling pathways which is critical to EMT induction. TGF $\beta$ signaling is the most characterized pathway which can induce EMT programme, therefore, inhibitors targeting this pathway has been already developed and some of them are being tested in clinical trials ${ }^{[56]}$. On the other hand, Jiao et al ${ }^{[57]}$ investigated the effectiveness of curcumin, a hepatocyte growth factor (HGF) inhibitor, based on the notion that HGF signaling also contributes to EMT induction. They reported that curcumin treatment induced expression of epithelial marker E-cadherin and inhibited tumor progression, indicating the possibility that we can inhibit EMT programme by targeting HGF signaling.

\section{Hypoxia and low reactive oxygen species (ROS) level}

Hypoxia has been reported to maintain CSCs in an undifferentiated state ${ }^{[58,59]}$. Jogi et al.$^{[58]}$, showed that in cells exposed to hypoxia, genes involved in stemness like Notch were upregulated while differentiated markers were downregulated. The main factors which correlate hypoxia and cancer stemness are HIFs. Human HIF family is composed of HIF $1 \alpha$, HIF $1 \beta$, HIF $2 \alpha$, HIF $2 \beta$, HIF $3 \alpha$ and HIF $3 \beta$. HIF $\alpha$ subunits undergo proteasome-dependent degradation in normal oxygen conditions (normoxia) and only in the hypoxic conditions, they form complex with HIF $\beta$ subunits and become stabilized ${ }^{[60]}$. After HIF complex is formed, it moves into the nucleus and binds to the Hypoxia Response Element gene promoters to activate HIF-regulated genes.

Among the HIF family members, HIF1 $\alpha$ and HIF2 $\alpha$ are regarded to be important for maintaining cancer stemness. Although the DNA binding sites of the two proteins closely resemble, some of the target genes are unique to either HIF1 $\alpha$ or HIF2 $\alpha$. In general, HIF1 $\alpha$ activates survival genes in low oxygen conditions and HIF2 $\alpha$ binds to the promoter of stemness related genes like Oct- 4 and Nanog ${ }^{[59,61]}$. Heddleston et al..$^{[59]}$, directly showed that forced expression of non-degradable HIF2 $\alpha$ in glioma cells induced those cancer stem cell markers expression.

Researchers have investigated the effectiveness of HIF inhibitors. In order to obtain the proof of concept, Burkitt et al. ${ }^{[62]}$ compared the effect of sunitinib, a small molecule multitargeted receptor tyrosine kinase inhibitor, on colon cancer with or without disruption of HIF1 $\alpha$ and/or HIF2 $\alpha$ genes. They found that cells depleted HIF1 $\alpha$ or HIF2 $\alpha$, or both of them showed improved therapeutic response to sunitinib and complete remission rate raised to $50 \%$ of tested mice. Based on the findings like this, some HIF1 inhibitors including BAY 87-2243, 2-Methoxyestradiol and PX-478 2 HCl are currently tested in clinical trials.

In addition to direct targeting of HIFs, upstream regulator like phosphatidylinositol-3 kinase (PI3K)/ Akt signaling axis can be inhibited to downregulate the function of HIF1 $\alpha$ and HIF2 $\alpha$. Under hypoxic 
conditions, it is reported that PI3K phosphorylates Akt, which then activate gene expressions of HIF1 $\alpha$ and HIF $2 \alpha^{[63,64]}$. Therefore, inhibition of this signaling axis may contribute to eradicate CSCs by decreasing the function of HIF $1 \alpha$ and HIF $2 \alpha$. According to reports by Desalvo et al ${ }^{[65]}$ and Zhang et al. ${ }^{[66]}$, PI3K/Akt signaling pathway inhibitors enhanced the therapeutic efficacy of 2-deoxy-D-glucose, which is a compound that inhibits glycolysis. In addition, BEZ235, which is a dual inhibitor of PI3K and mammalian target of rapamycin (mTOR), was shown to be effective to suppress the stemness of CSCs in colon cancer by inhibiting PI3K/Akt/mTOR signaling ${ }^{[67]}$.

Interestingly, Liu et al ${ }^{[68]}$ reported that E3 ubiquitin ligase Parkin, of which mutation is strongly linked to familial Parkinson's disease, interacted with HIF1 $\alpha$ and promoted degradation of HIF1 $\alpha$ through ubiquitination. MDA-MB-231 breast cancer cells overexpressing Perkin showed much less ability to metastasize to lung than control MDA-MB-231 cells. Their results indicated that downregulating HIF1a function by modulating Perkin expression could hamper the CSC activity.

For both normal cells and cancer cells, accumulation of ROS causes cell death. However, it is known that in CSCs, ROS level is maintained relatively low by the enhanced expression of aldehyde dehydrogenase $(\mathrm{ALDH})^{[69]}$. ALDH decreases oxidative stress, particularly caused by aldehydes ${ }^{[70]}$. As high expression level of ALDH correlates with high tumorigenicity and resistance to chemotherapeutic drugs, it is widely used as a CSC marker ${ }^{[71-73]}$. Also, according to reports by Croker et al. ${ }^{[74]}$, the specific ALDH inhibitor diethylaminobenzaldehyde sensitized $\mathrm{ALDH}^{\text {high }} / \mathrm{CD} 44^{+}$breast cancer cells to chemotherapy and radiotherapy. ALDH, therefore, could be a potential drug target of CSCs as well as a molecular marker.

\section{Overexpression of ATP-binding cassette (transporter proteins}

Among many types of transporter proteins, ATP-binding cassette (ABC) transporter family, with 49 family members classified in 7 gene subfamilies, plays important roles for inducing drug resistance of cancer cells ${ }^{[75]}$. Most ABC transporters mediate the transport of substrate proteins (including drugs) across the plasma membrane using energy obtained by ATP hydrolysis. Overexpression of these ABC transporters has been reported in some types of cancers and especially in $\operatorname{CSCS}^{[76,77]}$.

Several signaling pathways are reported to be involved in the expression of $\mathrm{ABC}$ transporters. Some members including ABCC1 and ABCC4 are positively regulated Myc, while ABCC 3 is negatively regulated by $\mathrm{it}^{[78]}$. The stemness-related transcription factor Oct- 4 also control gene expression of ABC family members ${ }^{[79]}$. In addition, HMGA1, which is essential for the cellular reprogramming of somatic cells to induced pluripotent stem cells, was reported to regulate ABCG2 promoter activity through HMGA1 binding sites ${ }^{[80]}$. Chun et al. ${ }^{[81]}$ showed that inhibition of EGFR/HER2 signaling by lapatinib suppressed expression of $\mathrm{ABCB} 1$ and $\mathrm{ABCG}$, leading to sensitize breast cancer tumorsphere cells to doxorubicin. Nakanishi et al. ${ }^{[82]}$ also reported that by inhibiting BCR-ABL and its downstream PI3K/Akt signaling pathway, the protein level of ABCG2 was downregulated in chronic myelogenous leukemia cell.

Because the functions of $\mathrm{ABC}$ transporters are involved in the clinical multi drug resistance, combination therapies of $A B C$ transporter inhibitors and some anti-cancer drugs have been tested. The inhibitor of ABCG2 induced the drug efficacy of mitoxantrone and topotecan to lung cancer cells which overexpress $\mathrm{ABC}$ transporters ${ }^{[83]}$. Rabindran et al. ${ }^{[84]}$ checked that Fumitremorgin $\mathrm{C}$ reversed the sensitivities to mitoxantrone, doxorubicin, and topotecan through inhibiting the function of ABCG2. However, as normal tissue stem cells are also maintained by the upregulated expression of $\mathrm{ABC}$ transporters, inhibition of the transporter family will be harmful for those cells. Furthermore, brain microvessel endothelial cells, which constitute blood brain barriers, are known to be maintained by $\mathrm{ABC}$ transporters including $\mathrm{ABCG} 2$ and $\mathrm{ABCB1}{ }^{[85]}$. Therefore, eliminating CSCs by the inhibition of $\mathrm{ABC}$ transporters might be a double-edged sword. 


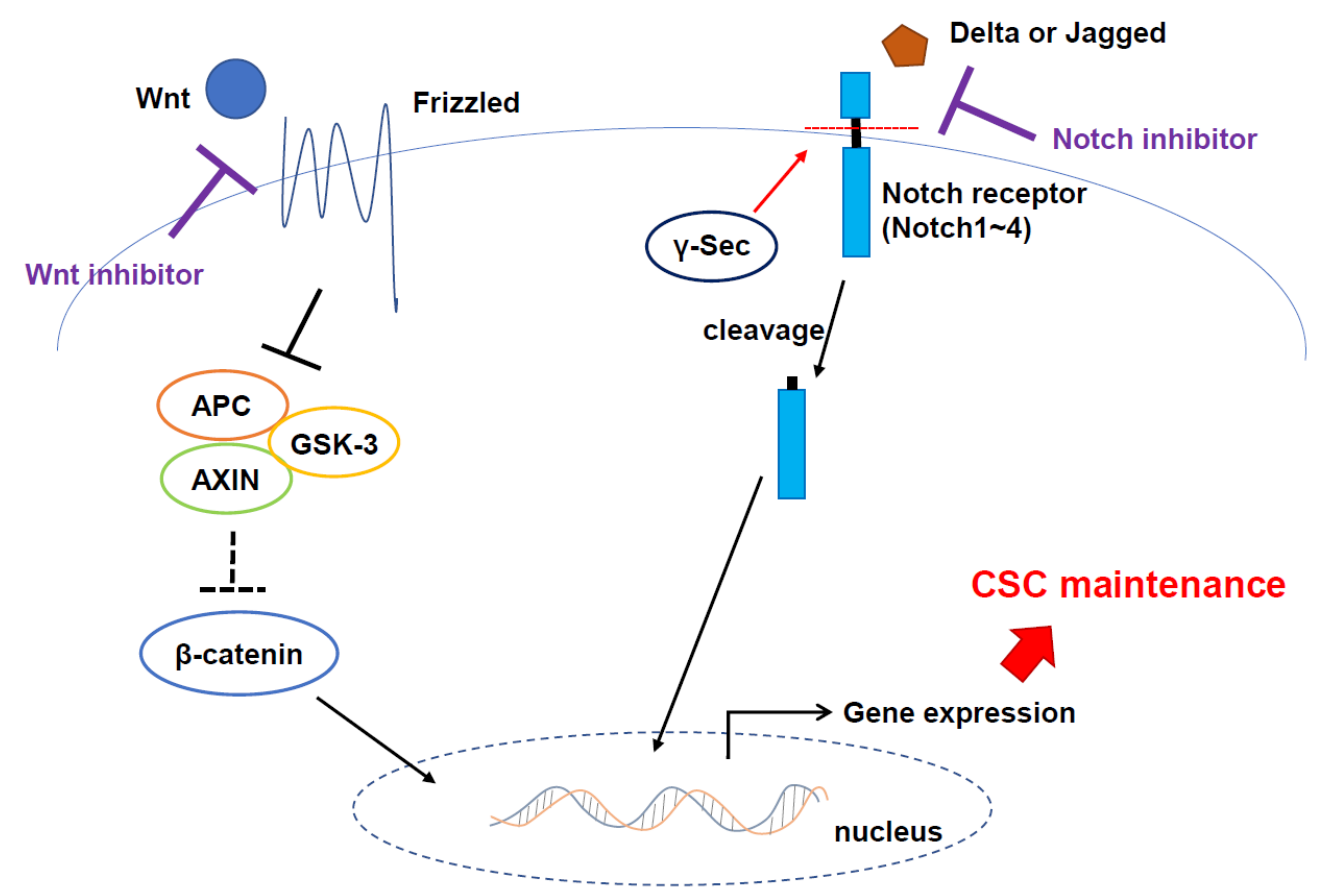

Figure 3. Stemness related pathways could be useful for targeting CSCs. When Wnt binds to FZD receptor, it downregulates the function of AXIN/GSK-3/APC complex, which leads to stabilization of $\beta$-catenin. Stabilized $\beta$-catenin moves into nucleus and induces the stemness related gene expressions. When a transmembrane Notch ligand (Delta or Jagged) on one cell binds to a transmembrane receptor (Notches 1-4) on a neighboring cell, the receptor is cleaved and interact with nuclear factors to regulate stemness related gene expressions. Inhibition of these pathways may contribute to CSC eradication. FZD: frizzled; GSK-3: glycogen synthase kinase-3; APC: adenomatous polyposis coli. CSCs: cancer stem-like cells

\section{Enhanced anti-apoptotic signaling and defective pro-apoptotic signaling}

CSCs also depend on the signaling pathways which contribute to preventing their apoptosis. Two major stemness related signaling pathways Notch and Hedgehog, which are often highly activated in CSCs, are shown to activate anti-apoptotic signaling. Domingo-Domenech et al. ${ }^{[86]}$ found that a subpopulation that survived Docetaxel treatment overexpressed molecules in the Notch and Sonic Hedgehog signaling pathways, and when these two pathways were inhibited, the resistant subpopulation was depleted through downregulation of Akt and B-cell lymphoma 2 (Bcl-2) expression. Bcl-2 itself is also thought to be important factor for pro-survival signaling and its upregulation has been confirmed in $\mathrm{CSCs}^{[87,88]}$.

In addition, genes inducing cell death are often dysregulated in CSCs. One of the leading factors regulating cell death is p53. When DNA damage or abnormal cell cycle progression is monitored, p53 is stabilized and activated ${ }^{[89]}$. Activated 553 then binds to DNA and induces expression of several genes involved in apoptosis. In CSCs, p53 downregulation or mutation can be often observed, which lead to the inappropriate regulation of cell death ${ }^{[0,91]}$. Restoration of normal p53 function is, therefore, one of the promising strategies to deprive CSCs of their therapeutic resistance ${ }^{[91]}$.

\section{TREATMENT APPROACHES TARGETING STEMNESS RELATED SIGNALING}

Because CSCs have potential to survive many kinds of conventional therapies, new therapeutic strategies to eradicate CSCs are now under investigation [Figure 3]. One way targeting CSCs is to inhibit the signaling pathways highly activated in those cells. Many types of Wnt signaling inhibitors, which targets ligandreceptor interaction ${ }^{[92,93]}$ or their downstream effectors porcupine ${ }^{[94]}$ or $\beta$-catenin ${ }^{[95]}$, have been developed, and some of them are now on the clinical trial. Notch signaling, another stemness related signaling pathway, is also a candidate target of CSCs. Curcumin, which is a natural compound produced by Curcuma 


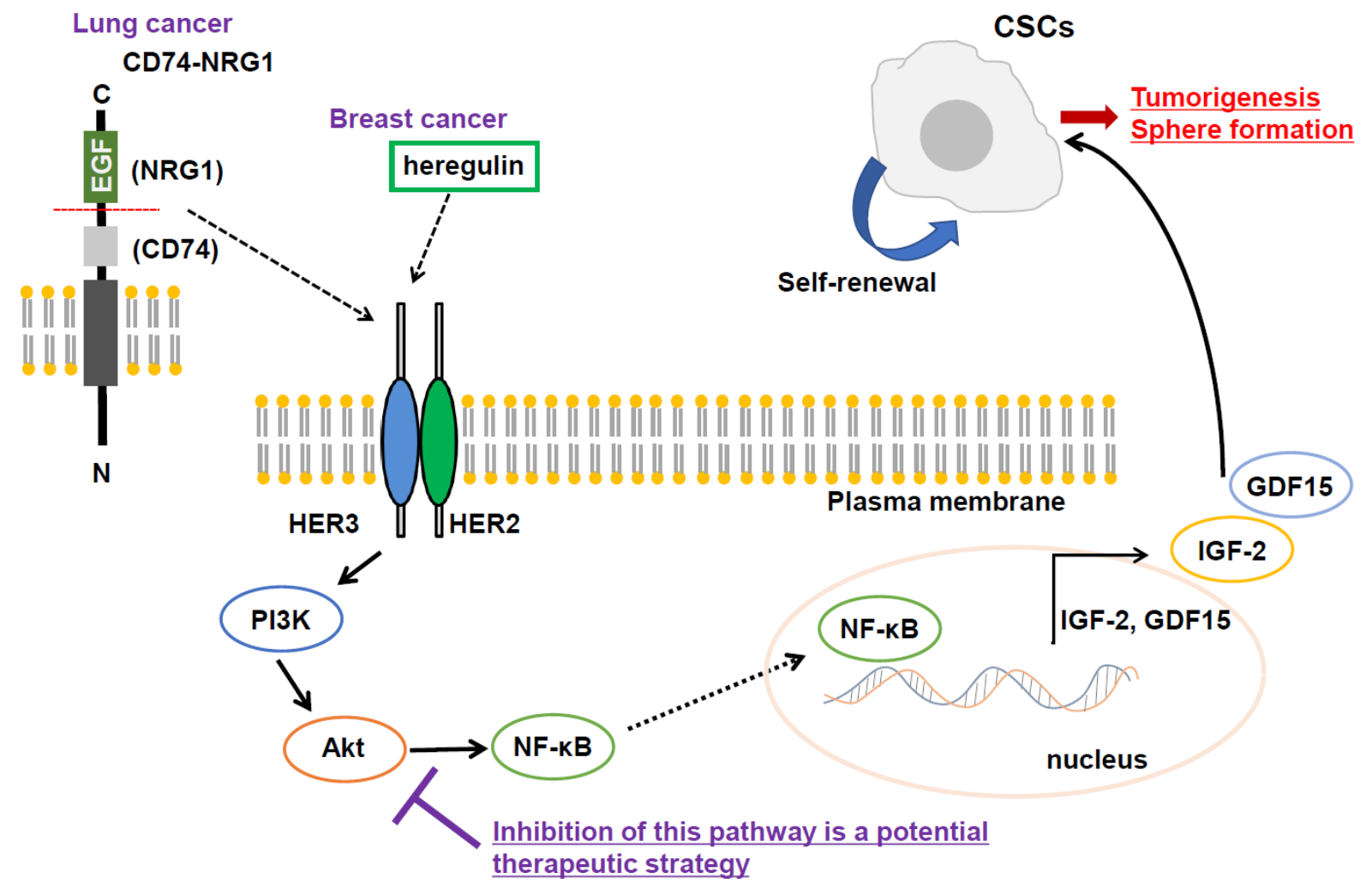

Figure 4. PI3K/Akt signaling pathway contributes to CSC maintenance and could be a promising target. When CD74-NRG1 fusion protein (in lung cancer) or heregulin (in breast cancer) binds to HER2/HER3 heterodimer receptor, PI3K/Akt/NF- $\mathrm{KB}$ signaling is activated. NF- $\mathrm{KB}$ induces gene expression of IGF-2 and growth differentiation factor 15 (GDF15), which enhances self-renewal ability of CSCs. Therefore, inhibition of this signaling pathway would be promising to target CSCs. IGF-2: insulin-like growth factor-2; GDF15: growth differentiation factor 15. CSCs: cancer stem-like cells

longa plants, has been reported to inhibit this pathway ${ }^{[96]}$. In addition, inhibitors targeting Notch pathway has been developed and efficacy on CSC eradication of the drugs have been suggested ${ }^{[97]}$.

TREATMENT APPROACHES TARGETING OTHER ACTIVATED SIGNALING PATHWAYS IN CSCS

Not limited to these stemness related signaling pathways, other activated signaling could be targeted. PI3K/ Akt signaling plays a crucial role in proliferation and survival of cancer cells during tumorigenesis ${ }^{[8 s]}$. We previously showed that PI3K/Akt signaling pathway activated by newly identified CD74-NRG1 fusion gene products contributed to maintenance and growth of CSCs in lung cancer ${ }^{[99,100]}$. By blocking this signaling pathway with PI3K inhibitor, the self-renewal activity of CSCs significantly suppressed. We have also shown that PI3K/Akt signaling pathway, which is activated by heregulin, contributes to the maintenance of CSCs in breast cancer ${ }^{[101]}$. Insulin-like growth factor-2 (IGF-2) ${ }^{[102]}$ and growth differentiation factor 15 $(\mathrm{GDF} 15)^{[103]}$, downstream factors of heregulin/PI3K/Akt, have been shown to play important roles in CSC maintenance [Figure 4].

MAPK-ERK signaling pathway is also important for CSC maintenance. Ding et al.$^{[104]}$ made it clear that $\mathrm{CD}_{133^{+}} \mathrm{CSC}$ s in liver cancer demonstrated higher resistance to TGF- $\beta$ induced apoptosis than CD133 nonCSCs. In their study, MAPK-ERK pathway inhibition effectively decreased CD $133^{+}$CSC population, thus, targeting signaling pathways highly activated in CSCs would be promising for CSC eradication.

Recently, we have reported that semaphorin signaling via MICAL3/collapsin response mediator protein 2 (CRMP2)/Numb axis contributes to the maintenance of breast CSCs by inducing symmetric cell division ${ }^{[105]}$. 

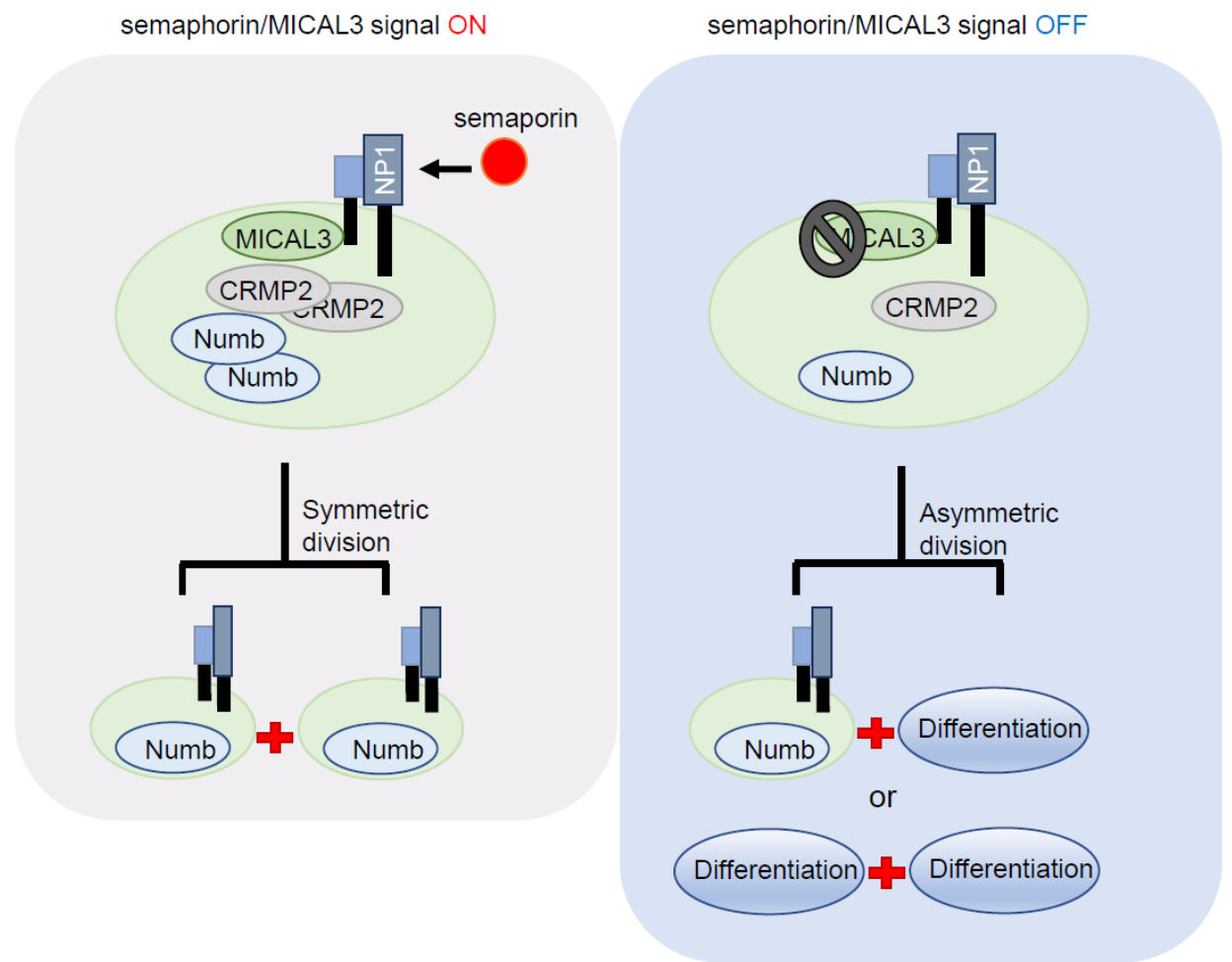

Figure 5. Semaphorin/MICAL3 signaling induces symmetric division of CSCs. By semaphorin binding to neuropilin 1 (NP1) receptor, MICAL3/collapsin response mediator protein 2 (CRMP2)/Numb axis is activated, leading to symmetric division and expansion of BCSCs. NP1: neuropilin 1; CRMP2: collapsin response mediator protein 2. CSCs: cancer stem-like cells

Depletion or inhibition of factors included in the semaphoring/MICAL3 signaling pathway increased asymmetric cell division of CSCs, which indicated that targeting this pathway could lead to eradication of CSCs [Figure 5].

\section{CSC TARGETING STRATEGY FOCUSING IMMUNE SYSTEM}

Furthermore, targeting CSCs by immunotherapy has recently been a hot topic ${ }^{[106]}$. One potential approach is to generate T-cell responses. In this strategy, CSCs isolated from patient tumors are loaded onto dendritic cells (DCs), which could be used as a cancer vaccine. Lu et al. ${ }^{[107]}$ showed the efficacy of CSC-DC vaccine by using the melanoma and squamous cell carcinoma mouse models. They enriched CSCs for vaccine production based on high expression level of $\mathrm{ALDH}$, and administration of the CSC-DC vaccine significantly decreased tumor volume, $\mathrm{ALDH}^{\text {high }} \mathrm{CSC}$ frequency and the probability of metastasis. Based on success of preclinical studies including this one, clinical studies of CSC-DC vaccine therapy are now ongoing.

\section{CONCLUSION}

CSCs show higher resistance to conventional chemotherapies and radiotherapies by staying in a dormant state, decreasing intra-cellular ROS levels, inducing export of toxic agents out of cells, or utilizing many other mechanisms as summarized in this review. Although accumulating knowledge on CSC features may enable us to target CSCs efficiently, there are still many challenges to be overcome. First, we have to distinguish the ways that will not damage normal tissue stem cells, which may not lead to the severe side effects. Second, as killing only CSCs could not succeed in complete tumor eradication, developing efficient combinational therapies will be needed. Therefore, it will take long time before the CSC targeting therapy 
started to be used widely in clinical settings. Though, once such a strategy is established, much more efficient tumor therapy will come true in the future.

\section{DECLARATIONS}

\section{Acknowledgments}

We thank all the members of our laboratory for their discussion on the contents of drug resistance of CSCs.

\section{Authors' contributions}

Conceptualization: Gotoh N

Writing-original draft preparation: Murayama $\mathrm{T}$

Writing-review and editing: Gotoh N

Supervision: Gotoh N

Project administration: Gotoh N

\section{Availability of data and materials}

Not applicable.

\section{Financial support and sponsorship}

This work was supported in part by a Grant-in-Aid for Scientific Research from a Japan Society for Promotion of Science (JSPS) (17K19587; 18H02679); a research grant from Japan Agency for Medical Research and Development (AMED) Project for Cancer Research and Therapeutic Evolution (P-CREATE) (No. 16cm0106120h0001); Practical Research for Innovative Cancer Control (No. 16ck0106194hoo01) to Gotoh N.

\section{Conflicts of interest}

All authors declared that there are no conflicts of interest.

\section{Ethical approval and consent to participate}

Not applicable.

\section{Consent for publication}

Not applicable.

\section{Copyright}

(c) The Author(s) 2019.

\section{REFERENCES}

1. Kreso A, Dick JE. Evolution of the cancer stem cell model. Cell Stem Cell 2014;14:275-91.

2. Dallas NA, Xia L, Fan F, Gray MJ, Gaur P, et al. Chemoresistant colorectal cancer cells, the cancer stem cell phenotype, and increased sensitivity to insulin-like growth factor-I receptor inhibition. Cancer Res 2009;69:1951-7.

3. Bao S, Wu Q, McLendon RE, Hao Y, Shi Q, et al. Glioma stem cells promote radioresistance by preferential activation of the DNA damage response. Nature 2006;444:756-60.

4. Rosa R, D’Amato V, De Placido S, Bianco R. Approaches for targeting cancer stem cells drug resistance. Expert Opin Drug Discov 2016;11:1201-12.

5. Akbarzadeh M, Maroufi NF, Tazehkand AP, Akbarzadeh M, Bastani S, et al. Current approaches in identification and isolation of cancer stem cells. J Cell Physiol 2019. doi: 10.1002/jcp.28271. [Epub ahead of print].

6. Abbaszadegan MR, Bagheri V, Razavi MS, Momtazi AA, Sahebkar A, et al. Isolation, identification, and characterization of cancer stem cells: A review. J Cell Physiol 2017;232:2008-18.

7. Lapidot T, Sirard C, Vormoor J, Murdoch B, Hoang T, et al. A cell initiating human acute myeloid leukaemia after transplantation into 
SCID mice. Nature 1994;367:645-8.

8. Bonnet D, Dick JE. Human acute myeloid leukemia is organized as a hierarchy that originates from a primitive hematopoietic cell. Nat Med 1997;3:730-7.

9. Al-Hajj M, Wicha MS, Benito-Hernandez A, Morrison SJ, Clarke MF. Prospective identification of tumorigenic breast cancer cells. Proc Natl Acad Sci U S A 2003;100:3983-8.

10. Singh SK, Hawkins C, Clarke ID, Squire JA, Bayani J, et al. Identification of human brain tumour initiating cells. Nature 2004;432:396-401.

11. Collins AT, Berry PA, Hyde C, Stower MJ, Maitland NJ. Prospective identification of tumorigenic prostate cancer stem cells. Cancer Res 2005;65:10946-51.

12. Dalerba P, Dylla SJ, Park IK, Liu R, Wang X, et al. Phenotypic characterization of human colorectal cancer stem cells. Proc Natl Acad Sci U S A 2007;104:10158-63.

13. Ricci-Vitiani L, Lombardi DG, Pilozzi E, Biffoni M, Todaro M, et al. Identification and expansion of human colon-cancer-initiating cells. Nature 2007;445:111-5.

14. O'Brien CA, Pollett A, Gallinger S, Dick JE. A human colon cancer cell capable of initiating tumour growth in immunodeficient mice. Nature 2007;445:106-10.

15. Eramo A, Lotti F, Sette G, Pilozzi E, Biffoni M, et al. Identification and expansion of the tumorigenic lung cancer stem cell population. Cell Death Differ 2008;15:504-14.

16. Luo M, Clouthier SG, Deol Y, Liu S, Nagrath S, et al. Breast cancer stem cells: current advances and clinical implications. Methods Mol Biol 2015;1293:1-49.

17. Munro MJ, Wickremesekera SK, Peng L, Tan ST, Itinteang T. Cancer stem cells in colorectal cancer: a review. J Clin Pathol 2018;71:110-6.

18. Lathia JD, Mack SC, Mulkearns-Hubert EE, Valentim CL, Rich JN. Cancer stem cells in glioblastoma. Genes Dev 2015;29:1203-17.

19. Brown HK, Tellez-Gabriel M, Heymann D. Cancer stem cells in osteosarcoma. Cancer Lett 2017;386:189-95.

20. Magee JA, Piskounova E, Morrison SJ. Cancer stem cells: impact, heterogeneity, and uncertainty. Cancer Cell 2012;21:283-96.

21. Takebe N, Miele L, Harris PJ, Jeong W, Bando H, et al. Targeting Notch, Hedgehog, and Wnt pathways in cancer stem cells: clinical update. Nat Rev Clin Oncol 2015;12:445-64.

22. Majidinia M, Aghazadeh J, Jahanban-Esfahlani R, Yousefi B. The roles of Wnt/beta-catenin pathway in tissue development and regenerative medicine. J Cell Physiol 2018;233:5598-612.

23. Park JI, Venteicher AS, Hong JY, Choi J, Jun S, et al. Telomerase modulates Wnt signalling by association with target gene chromatin. Nature 2009;460:66-72.

24. Beachy PA, Hymowitz SG, Lazarus RA, Leahy DJ, Siebold C. Interactions between Hedgehog proteins and their binding partners come into view. Genes Dev 2010;24:2001-12.

25. Ng JM, Curran T. The Hedgehog's tale: developing strategies for targeting cancer. Nat Rev Cancer 2011;11:493-501.

26. Lei J, Ma J, Ma Q, Li X, Liu H, et al. Hedgehog signaling regulates hypoxia induced epithelial to mesenchymal transition and invasion in pancreatic cancer cells via a ligand-independent manner. Mol Cancer 2013;12:66.

27. Lei J, Fan L, Wei G, Chen X, Duan W, et al. Gli-1 is crucial for hypoxia-induced epithelial-mesenchymal transition and invasion of breast cancer. Tumour Biol 2015;36:3119-26.

28. Ranganathan P, Weaver KL, Capobianco AJ. Notch signalling in solid tumours: a little bit of everything but not all the time. Nat Rev Cancer 2011;11:338-51.

29. Gu JW, Rizzo P, Pannuti A, Golde T, Osborne B, et al. Notch signals in the endothelium and cancer "stem-like" cells: opportunities for cancer therapy. Vasc Cell 2012;4:7.

30. Farnie G, Clarke RB. Mammary stem cells and breast cancer--role of Notch signalling. Stem Cell Rev 2007;3:169-75.

31. Fan X, Khaki L, Zhu TS, Soules ME, Talsma CE, et al. NOTCH pathway blockade depletes CD133-positive glioblastoma cells and inhibits growth of tumor neurospheres and xenografts. Stem Cells 2010;28:5-16.

32. Calabrese C, Poppleton H, Kocak M, Hogg TL, Fuller C, et al. A perivascular niche for brain tumor stem cells. Cancer Cell 2007;11:69-82.

33. Driessens G, Beck B, Caauwe A, Simons BD, Blanpain C. Defining the mode of tumour growth by clonal analysis. Nature 2012;488:527-30.

34. Yan M. Therapeutic promise and challenges of targeting DLL4/NOTCH1. Vasc Cell 2011;3:17.

35. Saito N, Fu J, Zheng S, Yao J, Wang S, et al. A high Notch pathway activation predicts response to gamma secretase inhibitors in proneural subtype of glioma tumor-initiating cells. Stem Cells 2014;32:301-12.

36. Messersmith WA, Shapiro GI, Cleary JM, Jimeno A, Dasari A, et al. A Phase I, dose-finding study in patients with advanced solid malignancies of the oral gamma-secretase inhibitor PF-03084014. Clin Cancer Res 2015;21:60-7.

37. Lawson DA, Bhakta NR, Kessenbrock K, Prummel KD, Yu Y, et al. Single-cell analysis reveals a stem-cell program in human metastatic breast cancer cells. Nature 2015;526:131-5.

38. Shafee N, Smith CR, Wei S, Kim Y, Mills GB, et al. Cancer stem cells contribute to cisplatin resistance in Brca1/p53-mediated mouse mammary tumors. Cancer Res 2008;68:3243-50.

39. Thakur B, Ray P. Cisplatin triggers cancer stem cell enrichment in platinum-resistant cells through NF-kappaB-TNFalpha-PIK3CA loop. J Exp Clin Cancer Res 2017;36:164.

40. Chen S, Song X, Chen Z, Li X, Li M, et al. CD133 expression and the prognosis of colorectal cancer: a systematic review and meta- 
analysis. PLoS One 2013;8:e56380.

41. Huang R, Mo D, Wu J, Ai H, Lu Y. CD133 expression correlates with clinicopathologic features and poor prognosis of colorectal cancer patients: An updated meta-analysis of 37 studies. Medicine (Baltimore) 2018;97:e10446.

42. Li X, Lewis MT, Huang J, Gutierrez C, Osborne CK, et al. Intrinsic resistance of tumorigenic breast cancer cells to chemotherapy. J Natl Cancer Inst 2008;100:672-9.

43. Chang JC, Wooten EC, Tsimelzon A, Hilsenbeck SG, Gutierrez MC, et al. Patterns of resistance and incomplete response to docetaxel by gene expression profiling in breast cancer patients. J Clin Oncol 2005;23:1169-77.

44. Sadanandam A, Lyssiotis CA, Homicsko K, Collisson EA, Gibb WJ, et al. A colorectal cancer classification system that associates cellular phenotype and responses to therapy. Nat Med 2013;19:619-25.

45. Carruthers RD, Ahmed SU, Ramachandran S, Strathdee K, Kurian KM, et al. Replication Stress Drives Constitutive Activation of the DNA Damage Response and Radioresistance in Glioblastoma Stem-like Cells. Cancer Res 2018;78:5060-71.

46. Carnero A, Garcia-Mayea Y, Mir C, Lorente J, Rubio IT. The cancer stem-cell signaling network and resistance to therapy. Cancer Treat Rev 2016;49:25-36.

47. Skvortsov S, Debbage P, Lukas P, Skvortsova I. Crosstalk between DNA repair and cancer stem cell (CSC) associated intracellular pathways. Semin Cancer Biol 2015;31:36-42.

48. Takeishi S, Nakayama KI. To wake up cancer stem cells, or to let them sleep, that is the question. Cancer Sci 2016;107:875-81.

49. Takeishi S, Matsumoto A, Onoyama I, Naka K, Hirao A, et al. Ablation of Fbxw7 eliminates leukemia-initiating cells by preventing quiescence. Cancer Cell 2013;23:347-61.

50. Prost S, Relouzat F, Spentchian M, Ouzegdouh Y, Saliba J, et al. Erosion of the chronic myeloid leukaemia stem cell pool by PPARgamma agonists. Nature 2015;525:380-3.

51. Shook D, Keller R. Mechanisms, mechanics and function of epithelial-mesenchymal transitions in early development. Mech Dev 2003;120:1351-83.

52. Mani SA, Guo W, Liao MJ, Eaton EN, Ayyanan A, et al. The epithelial-mesenchymal transition generates cells with properties of stem cells. Cell 2008;133:704-15.

53. Bill R, Christofori G. The relevance of EMT in breast cancer metastasis: Correlation or causality? FEBS Lett 2015;589:1577-87.

54. Nieto MA, Huang RY, Jackson RA, Thiery JP. Emt: 2016. Cell 2016;166:21-45.

55. Farmer P, Bonnefoi H, Anderle P, Cameron D, Wirapati P, et al. A stroma-related gene signature predicts resistance to neoadjuvant chemotherapy in breast cancer. Nat Med 2009;15:68-74.

56. Neuzillet C, Tijeras-Raballand A, Cohen R, Cros J, Faivre S, et al. Targeting the TGFbeta pathway for cancer therapy. Pharmacol Ther 2015;147:22-31.

57. Jiao D, Wang J, Lu W, Tang X, Chen J, et al. Curcumin inhibited HGF-induced EMT and angiogenesis through regulating c-Met dependent PI3K/Akt/mTOR signaling pathways in lung cancer. Mol Ther Oncolytics 2016;3:16018.

58. Jogi A, Ora I, Nilsson H, Lindeheim A, Makino Y, et al. Hypoxia alters gene expression in human neuroblastoma cells toward an immature and neural crest-like phenotype. Proc Natl Acad Sci U S A 2002;99:7021-6.

59. Heddleston JM, Li Z, McLendon RE, Hjelmeland AB, Rich JN. The hypoxic microenvironment maintains glioblastoma stem cells and promotes reprogramming towards a cancer stem cell phenotype. Cell Cycle 2009;8:3274-84.

60. Choudhry H, Harris AL. Advances in Hypoxia-Inducible Factor Biology. Cell Metab 2018;27:281-98.

61. Keith B, Johnson RS, Simon MC. HIF1alpha and HIF2alpha: sibling rivalry in hypoxic tumour growth and progression. Nat Rev Cancer 2011;12:9-22.

62. Burkitt K, Chun SY, Dang DT, Dang LH. Targeting both HIF-1 and HIF-2 in human colon cancer cells improves tumor response to sunitinib treatment. Mol Cancer Ther 2009;8:1148-56.

63. Joshi S, Singh AR, Zulcic M, Durden DL. A macrophage-dominant PI3K isoform controls hypoxia-induced HIF1alpha and HIF2alpha stability and tumor growth, angiogenesis, and metastasis. Mol Cancer Res 2014;12:1520-31.

64. Zhong H, Chiles K, Feldser D, Laughner E, Hanrahan C, et al. Modulation of hypoxia-inducible factor 1alpha expression by the epidermal growth factor/phosphatidylinositol 3-kinase/PTEN/AKT/FRAP pathway in human prostate cancer cells: implications for tumor angiogenesis and therapeutics. Cancer Res 2000;60:1541-5.

65. DeSalvo J, Kuznetsov JN, Du J, Leclerc GM, Leclerc GJ, et al. Inhibition of Akt potentiates 2-DG-induced apoptosis via downregulation of UPR in acute lymphoblastic leukemia. Mol Cancer Res 2012;10:969-78.

66. Zhang T, Zhu X, Wu H, Jiang K, Zhao G, et al. Targeting the ROS/PI3K/AKT/HIF-1alpha/HK2 axis of breast cancer cells: Combined administration of Polydatin and 2-Deoxy-d-glucose. J Cell Mol Med 2019;23:3711-23.

67. Chen J, Shao R, Li F, Monteiro M, Liu JP, et al. PI3K/Akt/mTOR pathway dual inhibitor BEZ235 suppresses the stemness of colon cancer stem cells. Clin Exp Pharmacol Physiol 2015;42:1317-26.

68. Liu J, Zhang C, Zhao Y, Yue X, Wu H, et al. Parkin targets HIF-1alpha for ubiquitination and degradation to inhibit breast tumor progression. Nat Commun 2017;8:1823.

69. Clark DW, Palle K. Aldehyde dehydrogenases in cancer stem cells: potential as therapeutic targets. Ann Transl Med 2016;4:518.

70. Vasiliou V, Pappa A, Estey T. Role of human aldehyde dehydrogenases in endobiotic and xenobiotic metabolism. Drug Metab Rev 2004;36:279-99.

71. House CD, Jordan E, Hernandez L, Ozaki M, James JM, et al. NFkappaB Promotes Ovarian Tumorigenesis via Classical Pathways That Support Proliferative Cancer Cells and Alternative Pathways That Support ALDH(+) Cancer Stem-like Cells. Cancer Res 2017;77:6927-40. 
72. Lin L, Jou D, Wang Y, Ma H, Liu T, et al. STAT3 as a potential therapeutic target in ALDH+ and CD44+/CD24+ stem cell-like pancreatic cancer cells. Int J Oncol 2016;49:2265-74.

73. Wu C, Zhu J, Zhang X. Integrating gene expression and protein-protein interaction network to prioritize cancer-associated genes. BMC Bioinformatics 2012;13:182.

74. Croker AK, Allan AL. Inhibition of aldehyde dehydrogenase (ALDH) activity reduces chemotherapy and radiation resistance of stemlike ALDHhiCD44(+) human breast cancer cells. Breast Cancer Res Treat 2012;133:75-87.

75. DeGorter MK, Xia CQ, Yang JJ, Kim RB. Drug transporters in drug efficacy and toxicity. Annu Rev Pharmacol Toxicol 2012;52:24973.

76. Begicevic RR, Falasca M. ABC Transporters in Cancer Stem Cells: Beyond Chemoresistance. Int J Mol Sci 2017;18:pii:E2362.

77. Li Y, Atkinson K, Zhang T. Combination of chemotherapy and cancer stem cell targeting agents: Preclinical and clinical studies. Cancer Lett 2017;396:103-9.

78. Porro A, Haber M, Diolaiti D, Iraci N, Henderson M, et al. Direct and coordinate regulation of ATP-binding cassette transporter genes by Myc factors generates specific transcription signatures that significantly affect the chemoresistance phenotype of cancer cells. J Biol Chem 2010;285:19532-43.

79. Oliveira BR, Figueiredo MA, Trindade GS, Marins LF. OCT4 mutations in human erythroleukemic cells: implications for multiple drug resistance (MDR) phenotype. Mol Cell Biochem 2015;400:41-50.

80. Kim DK, Seo EJ, Choi EJ, Lee SI, Kwon YW, et al. Crucial role of HMGA1 in the self-renewal and drug resistance of ovarian cancer stem cells. Exp Mol Med 2016;48:e255.

81. Chun SY, Kwon YS, Nam KS, Kim S. Lapatinib enhances the cytotoxic effects of doxorubicin in MCF-7 tumorspheres by inhibiting the drug efflux function of ABC transporters. Biomed Pharmacother 2015;72:37-43.

82. Nakanishi T, Shiozawa K, Hassel BA, Ross DD. Complex interaction of BCRP/ABCG2 and imatinib in BCR-ABL-expressing cells: BCRP-mediated resistance to imatinib is attenuated by imatinib-induced reduction of BCRP expression. Blood 2006;108:678-84.

83. Zhang W, Chen Z, Chen L, Wang F, Li F, et al. ABCG2-overexpressing H460/MX20 cell xenografts in athymic nude mice maintained original biochemical and cytological characteristics. Sci Rep 2017;7:40064.

84. Rabindran SK, Ross DD, Doyle LA, Yang W, Greenberger LM. Fumitremorgin C reverses multidrug resistance in cells transfected with the breast cancer resistance protein. Cancer Res 2000;60:47-50.

85. Fan Y, Liu X. Alterations in Expression and Function of ABC Family Transporters at Blood-Brain Barrier under Liver Failure and Their Clinical Significances. Pharmaceutics 2018;10:pii:E102.

86. Domingo-Domenech J, Vidal SJ, Rodriguez-Bravo V, Castillo-Martin M, Quinn SA, et al. Suppression of acquired docetaxel resistance in prostate cancer through depletion of notch- and hedgehog-dependent tumor-initiating cells. Cancer Cell 2012;22:373-88.

87. Goff DJ, Court Recart A, Sadarangani A, Chun HJ, Barrett CL, et al. A Pan-BCL2 inhibitor renders bone-marrow-resident human leukemia stem cells sensitive to tyrosine kinase inhibition. Cell Stem Cell 2013;12:316-28.

88. Hu Y, Yague E, Zhao J, Wang L, Bai J, et al. Sabutoclax, pan-active BCL-2 protein family antagonist, overcomes drug resistance and eliminates cancer stem cells in breast cancer. Cancer Lett 2018;423:47-59.

89. Yogosawa S, Yoshida K. Tumor suppressive role for kinases phosphorylating p53 in DNA damage-induced apoptosis. Cancer Sci 2018;109:3376-82.

90. Shetzer Y, Solomon H, Koifman G, Molchadsky A, Rotter V. The paradigm of mutant p53-expressing cancer stem cells and drug resistance. Carcinogenesis 2014;35:1196-208.

91. Prabhu VV, Allen JE, Hong B, Zhang S, Cheng H, et al. Therapeutic targeting of the p53 pathway in cancer stem cells. Expert Opin Ther Targets 2012;16:1161-74.

92. Gurney A, Axelrod F, Bond CJ, Cain J, Chartier C, et al. Wnt pathway inhibition via the targeting of Frizzled receptors results in decreased growth and tumorigenicity of human tumors. Proc Natl Acad Sci U S A 2012;109:11717-22.

93. Zhang S, Cui B, Lai H, Liu G, Ghia EM, et al. Ovarian cancer stem cells express ROR1, which can be targeted for anti-cancer-stemcell therapy. Proc Natl Acad Sci U S A 2014;111:17266-71.

94. Tammela T, Sanchez-Rivera FJ, Cetinbas NM, Wu K, Joshi NS, et al. A Wnt-producing niche drives proliferative potential and progression in lung adenocarcinoma. Nature 2017;545:355-9.

95. Zhou H, Mak PY, Mu H, Mak DH, Zeng Z, et al. Combined inhibition of beta-catenin and Bcr-Abl synergistically targets tyrosine kinase inhibitor-resistant blast crisis chronic myeloid leukemia blasts and progenitors in vitro and in vivo. Leukemia 2017;31:2065-74.

96. Wang Z, Zhang Y, Banerjee S, Li Y, Sarkar FH. Notch-1 down-regulation by curcumin is associated with the inhibition of cell growth and the induction of apoptosis in pancreatic cancer cells. Cancer 2006;106:2503-13.

97. Xiao W, Gao Z, Duan Y, Yuan W, Ke Y. Notch signaling plays a crucial role in cancer stem-like cells maintaining stemness and mediating chemotaxis in renal cell carcinoma. J Exp Clin Cancer Res 2017;36:41.

98. Yang J, Nie J, Ma X, Wei Y, Peng Y, et al. Targeting PI3K in cancer: mechanisms and advances in clinical trials. Mol Cancer 2019;18:26.

99. Murayama T, Nakaoku T, Enari M, Nishimura T, Tominaga K, et al. Oncogenic Fusion Gene CD74-NRG1 Confers Cancer Stem Celllike Properties in Lung Cancer through a IGF2 Autocrine/Paracrine Circuit. Cancer Res 2016;76:974-83.

100. Nakaoku T, Tsuta K, Ichikawa H, Shiraishi K, Sakamoto H, et al. Druggable oncogene fusions in invasive mucinous lung adenocarcinoma. Clin Cancer Res 2014;20:3087-93.

101. Hinohara K, Kobayashi S, Kanauchi H, Shimizu S, Nishioka K, et al. ErbB receptor tyrosine kinase/NF-kappaB signaling controls mammosphere formation in human breast cancer. Proc Natl Acad Sci U S A 2012;109:6584-9. 
102. Tominaga K, Shimamura T, Kimura N, Murayama T, Matsubara D, et al. Addiction to the IGF2-ID1-IGF2 circuit for maintenance of the breast cancer stem-like cells. Oncogene 2017;36:1276-86.

103. Sasahara A, Tominaga K, Nishimura T, Yano M, Kiyokawa E, et al. An autocrine/paracrine circuit of growth differentiation factor (GDF) 15 has a role for maintenance of breast cancer stem-like cells. Oncotarget 2017;8:24869-81.

104. Ding W, Mouzaki M, You H, Laird JC, Mato J, et al. CD133+ liver cancer stem cells from methionine adenosyl transferase 1A-deficient mice demonstrate resistance to transforming growth factor (TGF)-beta-induced apoptosis. Hepatology 2009;49:1277-86.

105. Tominaga K, Minato H, Murayama T, Sasahara A, Nishimura T, et al. Semaphorin signaling via MICAL3 induces symmetric cell division to expand breast cancer stem-like cells. Proc Natl Acad Sci U S A 2019;116:625-30.

106. Codd AS, Kanaseki T, Torigo T, Tabi Z. Cancer stem cells as targets for immunotherapy. Immunology 2018;153:304-14.

107. Lu L, Tao H, Chang AE, Hu Y, Shu G, et al. Cancer stem cell vaccine inhibits metastases of primary tumors and induces humoral immune responses against cancer stem cells. Oncoimmunology 2015;4:e990767. 